\title{
Automatic detection and validity of the sea-ice edge: An application of enhanced-resolution QuikScat/SeaWinds data
}

\author{
David G. Long \\ david_long@byu.edu \\ Jorg Haarpaintner \\ Rasmus T. Tonboe \\ Michael L. Van Woert
}

Follow this and additional works at: https://scholarsarchive.byu.edu/facpub

Part of the Electrical and Computer Engineering Commons

\section{Original Publication Citation}

Haarpaintner, J., et al. "Automatic Detection and Validity of the Sea-Ice Edge: An Application of Enhanced-Resolution QuikScat/SeaWinds Data." Geoscience and Remote Sensing, IEEE

Transactions on 42.7 (24): 1433-43

\section{BYU ScholarsArchive Citation}

Long, David G.; Haarpaintner, Jorg; Tonboe, Rasmus T.; and Van Woert, Michael L., "Automatic detection and validity of the sea-ice edge: An application of enhanced-resolution QuikScat/SeaWinds data" (2004). Faculty Publications. 428.

https://scholarsarchive.byu.edu/facpub/428

This Peer-Reviewed Article is brought to you for free and open access by BYU ScholarsArchive. It has been accepted for inclusion in Faculty Publications by an authorized administrator of BYU ScholarsArchive. For more information, please contact ellen_amatangelo@byu.edu. 


\title{
Automatic Detection and Validity of the Sea-Ice Edge: An Application of Enhanced-Resolution QuikScat/SeaWinds Data
}

\author{
Jörg Haarpaintner, Rasmus T. Tonboe, David G. Long, Senior Member, IEEE, and Michael L. Van Woert
}

\begin{abstract}
Sea-ice edge detection is an essential task at the different national ice services to secure navigation in ice-covered seas. Comparison between the Remund and Long ice mask image from enhanced-resolution QuikScat/SeaWinds (QS) products and the analyzed ice edge from high-resolution RADARSAT synthetic aperture radar has shown that the automatically determined QS ice mask underestimates the Arctic ice extent. QS data was statistically analyzed by colocating the data with ice charts around Greenland and with the National Aeronautics and Space Administration Team's Special Sensor Microwave/Imager (SSM/I) ice concentration algorithm over the whole Arctic region. All variables, i.e., the backscatter in vertical and horizontal polarization, the active polarization ratio (APR) and the daily standard deviation, are sensitive to ice types and are strongly correlated with ice concentration when the relationship is expressed in exponential form. Our study showed that the APR is especially suitable for ice-ocean separation, and a threshold of -0.02 was determined. An ice edge algorithm based on this APR threshold was developed using the other variables with conservative season-dependent thresholds to eliminate additional ocean noise. Also, the history of the ice cover is considered in order to detect single ice fields that are separated from the main Arctic pack ice. Validation with RADARSAT 1 and with the Advanced Very High Resolution Radiometer showed that the new algorithm successfully detects very low ice concentrations of about $10 \%$ during the entire year. The validity of the detected ice edge for near-real-time issues is also discussed in relation to the ice motion in the Marginal Ice Zone and the integration time necessary to produce the enhanced-resolution images. The new algorithm improves the automatic global ice edge resolution by a factor of two when compared to SSM/I products and could be used in both model initialization and data assimilation.
\end{abstract}

Index Terms-Arctic, backscatter, ice edge, polarization, scatterometer, sea ice.

\section{INTRODUCTION}

A RCTIC and Antarctic sea-ice cover play an important role in the earth's climate, primarily by insulating the ocean from the atmosphere and increasing the surface albedo. Sea-ice

Manuscript received October 30, 2003; revised March 4, 2004. The work of J. Haarpaintner was supported in part by National Aeronautics and Space Administration under Grant NAG 59366 with the University Corporation for Atmospheric Research and the National Ice Center.

J. Haarpaintner was with the National Ice Center, Washington, DC 20395 USA. He is now with the Norwegian Meteorological Institute, 9293 Troms $\varnothing$, Norway (e-mail: joergh@met.no).

R. T. Tonboe is with the Danish Meteorological Institute, 2100 København, Denmark (e-mail: rtt@dmi.dk).

D. G. Long is with the Microwave Earth Remote Sensing Laboratory, Brigham Young University, Provo, UT 84602 USA (e-mail: long@ee.byu.edu)

M. L. Van Woert is with the National Ice Center, Washington, DC 20395 USA

(e-mail: mvanwoert@natice.noaa.gov).

Digital Object Identifier 10.1109/TGRS.2004.828195 formation and the accompanying convective processes are also the main driving force for the global thermohaline circulation [2]. Densification of sea water by brine rejection as a result of intensive freezing is strongest in open water areas, such as leads and polynyas, inside the pack ice and along the Marginal Ice Zone (MIZ). The bottom-water formation produced by surface brine release depends on the bathymetry [3] and hence location [4]. Sea-ice extent is also a potential indicator of climate change. A 30-year ice extent record shows a decreasing trend in Arctic ice cover [5]. Additionally, fishing and commercial shipping activities as well as military submarine operations need reliable ice edge information for safety purposes. Hence, an accurate sea-ice edge determination is crucial for fine-scale geophysical modeling and for near-real-time operations. However, as the ice edge is unstable in time, the temporal validity of the estimated ice edge is often shorter than the time required to transfer the information to the operational user.

The United States National Ice Center (NIC) in Washington, DC provides biweekly information about global sea-ice condition and also supports regional operations on a daily basis. Sea-ice analysis at the NIC is done with high-resolution synthetic aperture radar (SAR) from RADARSAT 1 (RS), Operational Linescan System (OLS), and the Advanced Very High Resolution Radiometer (AVHRR), if available, but otherwise relies heavily on wide-swath passive and active microwave imagery and scatterometry for global analysis. The Norwegian Meteorological Institute (MET.NO) provides daily ice charts for the Barents Sea, mainly based on low-resolution Special Sensor Microwave/Imager (SSM/I) data, using a combination of the National Aeronautics and Space Administration (NASA)-Team (NT) algorithm and the bootstrap frequency mode algorithm [6], and AVHRR, if available. Since the summer of 2003, the ice edge in the MET.NO ice charts has been extracted from QuikScat/SeaWinds enhanced-resolution data using the algorithm described in this paper.

Passive microwave sensors have been operating since 1972 [7]. They include the Scanning Multichannel Microwave Radiometer (SMMR) beginning in 1978 and the SSM/I of the Defense Meteorological Satellite Program (DMSP) from 1987 to the present. Several sea-ice concentration algorithms have been developed, and their performance has been evaluated [8]. The NIC hybrid algorithm [9], for examples, combines the NT algorithm [10] for the inner pack and the calibration-validation algorithm [11] for the MIZ. Sea-ice concentration and extent from SSM/I also serve to initialize the U.S. Navy's sea-ice 
forecast model, the Polar Ice Prediction System (PIPS) [12]. The common resolution of SSM/I ice concentration algorithms is $25 \mathrm{~km}$, which is insufficient for many operational tasks and limits its use in regional fine-scale hydrographic and sea-ice models. Using the SSM/I 85-GHz channel, the NASA-Team 2 algorithm permits a resolution of $12.5 \mathrm{~km}$, but is more susceptible to large errors due to its higher sensitivity to atmospheric conditions such as water vapor and the effect of wind on the ocean [13]. In general, SSM/I cannot reliably detect thin ice, especially during the summer. These effects are particularly noticeable at the MIZ, where weather is especially severe and thin ice is the norm, making it difficult to retrieve an accurate ice edge.

The QuikScat/SeaWinds instrument (QS) [14] is a follow-up mission to the fan-beam NASA Scatterometer (NSCAT), that operated for nine months between 1996 and 1997. Originally developed for surface wind retrieval over the ocean, scatterometry proved to be a promising sensor for cryospheric studies as well [15]. With its wide swath, QS covers the complete Arctic and Antarctic regions on a daily basis, similar to the SSM/I. Doppler filtering and resolution enhancement algorithms [16], [17] increase the resolution of QS daily composites of the polar regions to 5-10 km. Remund and Long [18] further developed an automatic ice-ocean discrimination algorithm for NSCAT and adapted it to the QS instrument [1].

To analyze the performance of QS ice-ocean discrimination, first case studies were done to evaluate the automatic Remund and Long [1] ice mapping algorithm developed at Brigham Young University and henceforth referred to as "BYU algorithm. De Abreu et al. [19] showed that the retrieved BYU ice edge successfully maps heavy areas of pack ice with ice concentrations above $70 \%$, but it detects neither thin ice below $15-\mathrm{cm}$ thickness nor areas of low ice concentrations. Other algorithms that combine the active polarization ratio (APR) (see Section III for definition) of QuikScat L2B products and the SSM/I 19-GHz passive polarization ratio (PPR) have also been developed to detect new ice [20]. All algorithm development studies agreed that the polarization ratio (PR) is the single most efficient variable to distinguish ice from ocean; with [20] stating that the APR is rather more sensitive to ice concentration than to ice types. Thus, the APR also attracts our attention in this paper.

In this paper, we continue the evaluation of the QS data, analyzing in more detail the different QS variables, particularly the APR, and their relationship to sea-ice characteristics, namely ice concentration and ice type. We propose a refinement of the ice edge detection algorithm to detect also low ice concentrations. The paper is organized as follows. Section II briefly presents the near-real-time QS products and summarizes the BYU algorithm [1], [18]. In Section III, the QS products are statistically analyzed by colocation with Greenland ice charts and NT ice concentration in order to extract and present relationships to geophysical sea-ice parameters. We propose a refined sea-ice edge algorithm, henceforth referred to as the "new algorithm," in Section IV, and in Section $\mathrm{V}$ we compare and validate this new-ice edge with the BYU ice mask, RS and AVHRR images. A discussion of the validity of the ice edge follows in Section VI.
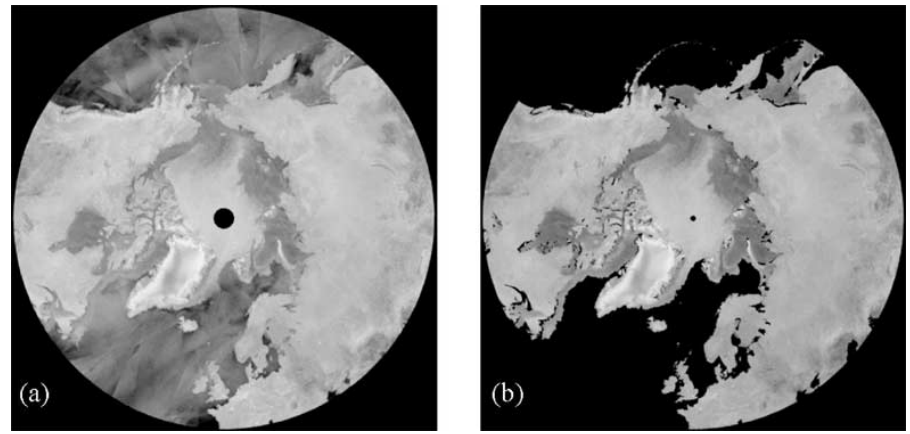

Fig. 1. Enhanced-resolution QS backscatter data in (a) HH polarization and (b) the BYU ice mask on March 11, 2003. ( ) NOAA/NESDIS/BYU

\section{NEAR-REAL-TIME QUiKSCAT/SEAWINDS ENHANCED-RESOLUTION PRODUCTS AND THE BYU ICE MASK}

\section{A. Near-Real-Time QuikScat/SeaWinds Products}

Launched in June 1999, QS is an active Ku-band dual-polarized, scanning pencil-beam microwave satellite-borne scatterometer operating in horizontal $(\mathrm{HH})$ and vertical (VV) polarizations [14]. The HH polarized inner scan and the VV polarized outer scan have incidence angles of $46^{\circ}$ and $54^{\circ}$, respectively. Emitting radar pulses at $13.4 \mathrm{GHz}$, this sensor is essentially independent of atmospheric conditions and daylight. Similar to the SAR, the backscattered signal of QS from the earth's surface is dependent on the roughness at the scale of the radar wavelength, the incidence angle, and the dielectric properties of the surface, which for sea ice means ice salinity, temperature, air inclusion, liquid water fraction in snow and ice, and snow cover [21]. Deformation processes like ridging and rafting also influence the backscatter. Backscatter is, therefore, a function of both ice concentration and ice type [22], [23]. Because of the higher salinity and reduced air bubble density of first-year ice (FYI), the backscatter from FYI is dominated by surface scattering, whereas volume scattering dominates the signal from multiyear ice (MYI) [24]. For Ku-band, snow cover becomes a significant scattering source for metamorphosed snow with large grains (about diameter $>1.2 \mathrm{~mm}$ ) and rough snow-ice at the snow/ice interface [25]. The increased liquid water fraction in the snow and ice surface during the melting season absorbs the microwaves and strongly decreases the backscatter. Ocean backscatter is dependent on wind speed and the wind direction relative to the radar look angle. At low wind speeds, $\mathrm{HH}$ backscatter from the ocean is generally lower than backscatter from ice $(<-23 \mathrm{~dB})$, but higher wind speeds may produce ambiguities for the ice-ocean discrimination because ice and ocean may exhibit similar mean backscatter values.

QS's wide swaths of 1800 and $1400 \mathrm{~km}$ in VV and HH, respectively, cover the whole Arctic and Antarctic on a daily basis. Range/Doppler filtering divides the nominal $25 \mathrm{~km} \times 37 \mathrm{~km}$ QS footprint into $25 \mathrm{~km} \times 6 \mathrm{~km}$ slices in the range direction. A single-variate form of the scatterometer image reconstruction (SIR) algorithm [26] further enhances the spatial resolution into a composite $2.225-\mathrm{km}$ grid image (with a nominal resolution of about $5-10 \mathrm{~km}$ ) by combining all satellite passes during a 36-h period. This time period ensures multiple-pass coverage at the lowest latitude within the imaging area (see Fig. 1). For near-real-time application, the resolution enhancement algorithm is simplified, and only averages the measure- 
ments over each pixel, taking into account the slice footprint, the antenna and beam pattern, and the signal contribution to each pixel. Non-real-time processing uses the full SIR algorithm and archived images are available from the Scatterometer Climate Record Pathfinder at http://www.scp.byu.edu/ [27]. The data used in this study have been processed daily in near real-time by the National Environmental Satellite Data and Information System (NESDIS) providing the following five 36-h-composite enhanced-resolution products at $2.225-\mathrm{km}$ pixel size [28]:

- VV backscatter $\sigma_{0 \mathrm{~V}}$ in decibels at an incident angle of $54^{\circ}$;

- HH backscatter $\sigma_{0 \mathrm{H}}$ in decibels at an incident angle of $46^{\circ}$ [Fig. 1(a)];

- daily standard deviation per pixel for VV $\left(\mathrm{STD}_{\mathrm{V}}\right)$;

- daily standard deviation per pixel for $\mathrm{HH}\left(\mathrm{STD}_{\mathrm{H}}\right)$;

- BYU ice mask built by combining the first four products.

These daily images with an effective spatial resolution of 5-10 $\mathrm{km}$ provide significantly more detail than the passive microwave SSM/I sensor with resolutions ranging from $15 \mathrm{~km}$ at $85 \mathrm{GHz}$ to $50 \mathrm{~km}$ at $19 \mathrm{GHz}$. The original BYU ice mask [Fig. 1(b)] algorithm [1], [18] is explained in Section II-B.

\section{B. Ice-Ocean Discrimination With QS (BYU Algorithm)}

Remund and Long [18] developed an ice-ocean discrimination algorithm for NSCAT that used the polarization ratio (PR), the vertical polarized incident dependency $\left(\mathrm{B}_{\mathrm{V}}\right)$, and both standard deviation images to automatically detect the ice edge. Since QS is a pencil-beam instrument instead of a fan-beam design, neither PR nor $\mathrm{B}_{\mathrm{V}}$ can be defined with $\mathrm{QS}$ data. The algorithm has been adapted for use with QS data by employing the QS pseudopolarization ratio $\left(\mathrm{PR}_{\mathrm{QS}}\right), \sigma_{\mathrm{OH}}$, and the standard deviation images [1] instead. However, since the VV and $\mathrm{HH}$ polarizations operate at two different incident angles, $54^{\circ}$ and $46^{\circ}$ respectively, the $\mathrm{PR}_{\mathrm{QS}}(1)$ reflects both the incidence angle dependency of $\sigma_{0}$ and the PR at the same angle

$$
\mathrm{PR}_{\mathrm{QS}}=\sigma_{0 \mathrm{~V}}(\mathrm{~dB})-\sigma_{0 \mathrm{H}}(\mathrm{dB})
$$

where $\sigma_{0 \mathrm{~V}}(\mathrm{~dB})$ and $\sigma_{\mathrm{OH}}(\mathrm{dB})$ are the backscatter values in decibels for $\mathrm{VV}$ and $\mathrm{HH}$ polarization, respectively.

Because sea ice is strongly isotropic [29], with a response of around $-0.25 \mathrm{~dB} /$ degree [1], the $8^{\circ}$ incidence-angle difference results in a $\mathrm{PR}_{\mathrm{QS}}$ roughly $2 \mathrm{~dB}$ lower than a usual $\mathrm{PR}$ at a constant incidence angle. In [18], the decision boundaries that separate ice from ocean are defined automatically between the ice and ocean modes in the $\mathrm{PR}_{\mathrm{QS}}$ versus $\sigma_{\mathrm{OH}}$ plane while the standard deviation images serve as a correction factor.

Comparison with the NT ice concentration showed that the ice edge extracted from the BYU ice mask corresponds to an average ice concentration between $40 \%$ and $60 \%$ during winter. Case studies with high-resolution RS data have shown, however, that this ice edge underestimates the ice extent, and misses important areas of thin ice and ice concentration below 70\% [19] that could present a potential risk to maritime operations.

\section{QS PARAMETERS AND THEIR GEOPHYSICAL ANALYSIS}

The active polarization ratio (APR) is defined by [20] as

$$
\mathrm{APR}=\left(\sigma_{0 \mathrm{H}}-\sigma_{0 \mathrm{~V}}\right) /\left(\sigma_{0 \mathrm{H}}+\sigma_{0 \mathrm{~V}}\right)
$$

where $\sigma_{0 \mathrm{H}}$ and $\sigma_{0 \mathrm{~V}}$ are the backscatter values expressed in power in linear scale, i.e., $\sigma_{\mathrm{OH}}=10^{(0 \mathrm{H}(\mathrm{dB}) / 10)}$. We note that like the $\mathrm{PR}_{\mathrm{QS}}$, the APR is a quasi-polarization ratio that combines both polarization and incidence angle variation. Earlier studies using NSCAT data have indicated that over sea ice $\sigma_{0 \mathrm{~V}}$ and $\sigma_{0 \mathrm{H}}$ are similar [30], and therefore, we expect the APR of sea ice to be a function primarily of the difference in the incidence angles of the two polarizations.

In order to extract geophysical signification for the QS variables, the $\sigma_{0 \mathrm{~V}}, \sigma_{0 \mathrm{H}}$ and APR images have been statistically analyzed by colocating the QS L2B BUFR data with Greenland sea-ice charts from the Danish Meteorological Institute (DMI) [23]. QS L2B BUFR data are near-real-time single-orbit wind and backscatter data in a $25 \mathrm{~km} \times 25 \mathrm{~km}$ wind cell grid. No resolution enhancement has been performed on these data. Six ice classes were extracted from the ice charts and divided into two ice types, MYI and FYI, at three ice concentration intervals: open $(0 \%$ to $30 \%)$, medium (30\% to $70 \%$ ), and closed (70\% to $100 \%)$. Their corresponding monthly means and standard deviations were calculated for each variable using a two-year time series of weekly ice charts. Since the QS L2B BUFR data already include the corresponding wind speed and direction over open ocean, their typical mean values have also been extracted in $5-\mathrm{m} / \mathrm{s}$ wind velocity bins. Fig. 2 compares the monthly values, showing that the APR for sea ice is positive and that the APR and the backscatter values increase with ice concentration. For the wind signature the backscatter increases with wind speed, and the APR is generally negative but close to zero at high wind speeds. During winter all the observation metrics exhibit a clear distinction between ice and ocean for low wind speed. The difference is evident for APR year round, even for low ice concentrations and high wind speeds. The average ocean backscatter values, $\sigma_{0 \mathrm{~V}}$ and $\sigma_{0 \mathrm{H}}$, for wind speeds less than $15 \mathrm{~m} / \mathrm{s}$ is lower than the average backscatter value of sea ice in winter. During summer the ice backscatter drops by about $5 \mathrm{~dB}$ due to surface melt and, therefore, diminishes the ice-ocean backscatter contrast. The APR does not present such a seasonal variation, having an ice-ocean contrast year round. Hence, the APR is the most reliable and, therefore, crucial variable to discriminate between ocean and ice. Nevertheless, the standard deviation of the APR is of order 0.1 for low ice concentration as well as for high wind speeds, meaning that there are still uncertainties in separating ocean under high wind speed from ice, resulting in "ocean noise," i.e., ocean misclassified as ice.

In order to study the dependency of QS variables on ice concentration, the QS data have been colocated with the NT ice concentration. Since all SSM/I ice concentration algorithms have their deficiencies, we have chosen the NT algorithm because it is the most commonly used. Data from the entire Arctic area gathered during the first of each month from October 2002 to August 2003 have been analyzed. STD and $\mathrm{STD}_{\mathrm{V}}$ have been combined into one variable of daily standard deviation, $\mathrm{STD}_{\max }$, taking the maximum of both daily standard deviations. The mean values and standard deviation of $\sigma_{0 \mathrm{~V}}, \sigma_{0 \mathrm{H}}$, the APR, and the $\mathrm{STD}_{\max }$ have been extracted for each ice concentration defined by the NT algorithm. To eliminate the land effect in the SSM/I data, the SSM/I land mask has been "dilated" by two pixels $(50 \mathrm{~km})$. Fig. 3 shows 


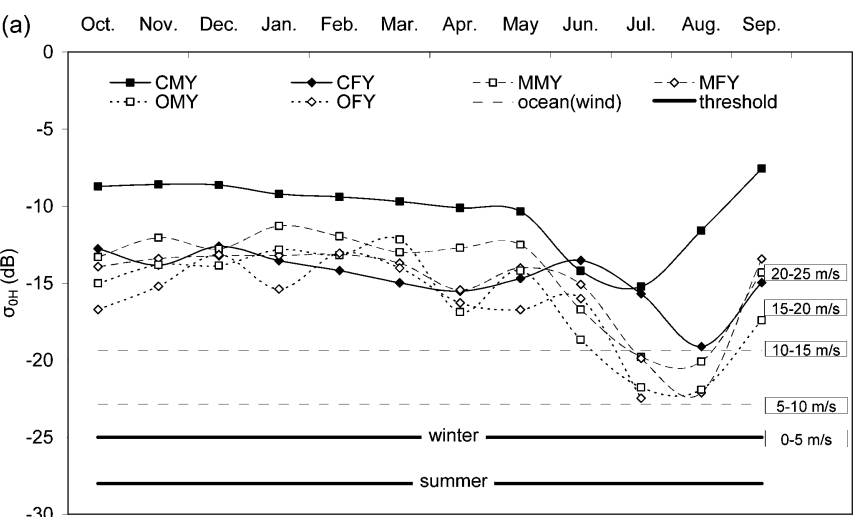

(b) Oct. Nov. Dec. Jan. Feb. Mar. Apr. May Jun. Jul. Aug. Sep.

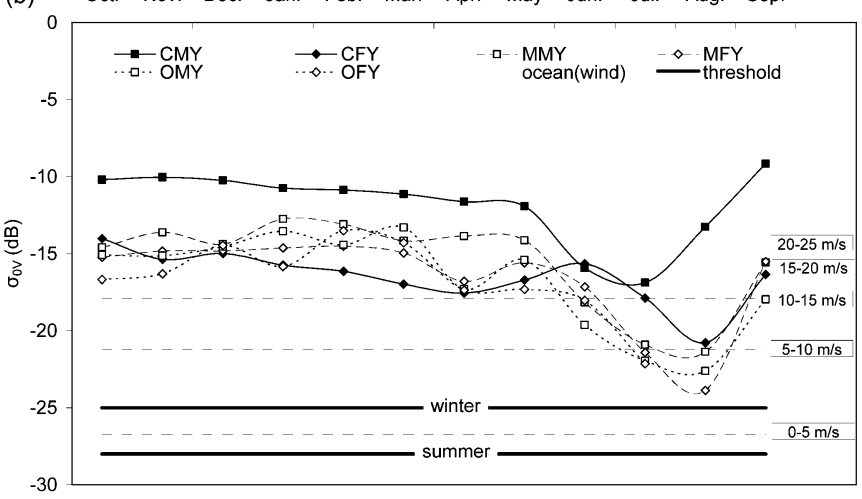

(c) Oct. Nov. Dec. Jan. Feb. Mar. Apr. May Jun. Jul. Aug. Sep.

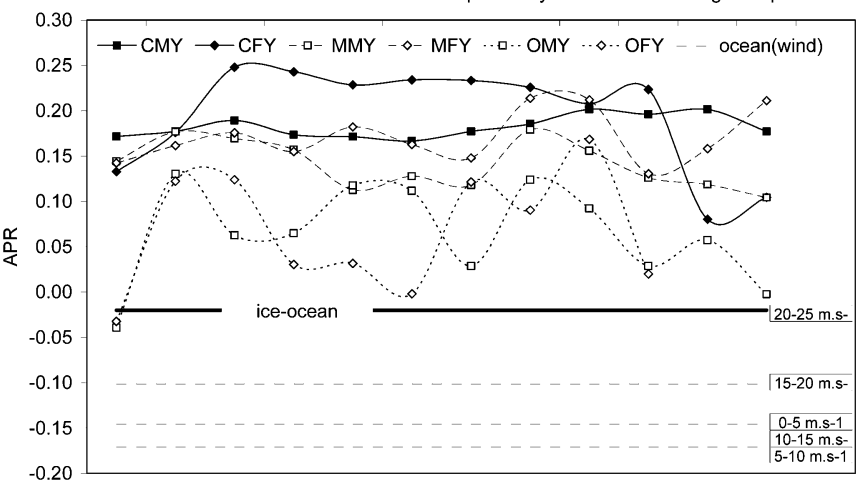

Fig. 2. Monthly mean values of the six ice classes, close MYI (CMY), close FYI(CFY), medium MYI (MMY), medium FYI (MFY), open MYI(OMY), and open FYI (OFY), for (a) $\sigma_{\mathrm{OH}}$, (b) $\sigma_{0 \mathrm{~V}}$, and (c) APR. Ice-ocean discrimination thresholds for winter and summer are marked as solid lines.

the resulting graphs, QS variables versus ice concentration. The thin lines represent the mean value for the first of each month. The mean values of each variable for each ice concentration over the whole period have been calculated (thick line), all showing high correlations above 0.93 with exponential regression lines. The HH and VV backscatter values (Fig. 3) are very dependent on surface changes during melting and refreezing periods and, therefore, produce a high seasonal variation over the whole range of ice concentration. A seasonal variation is also obvious in the daily standard deviation [Fig. 3(c)]. The thin lines representing the summer months (July and August) are 3-5 $\mathrm{dB}$ lower for $\sigma_{0 \mathrm{~V}}$ and $\sigma_{0 \mathrm{H}}$ and about 0.5 higher for the $\mathrm{STD}_{\max }$ (at ice concentrations above 60\%) than the colocation results for the rest of the year. As Fig. 2(c) shows, FYI has a

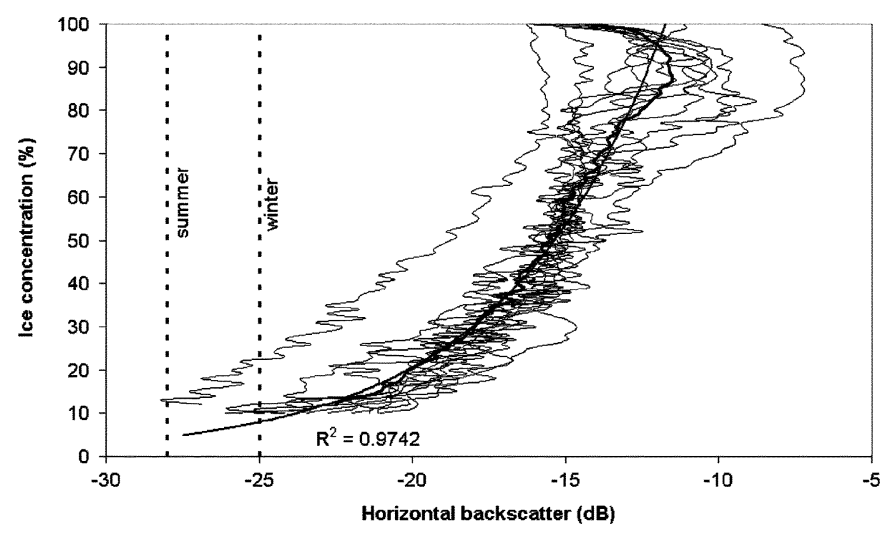

(a)

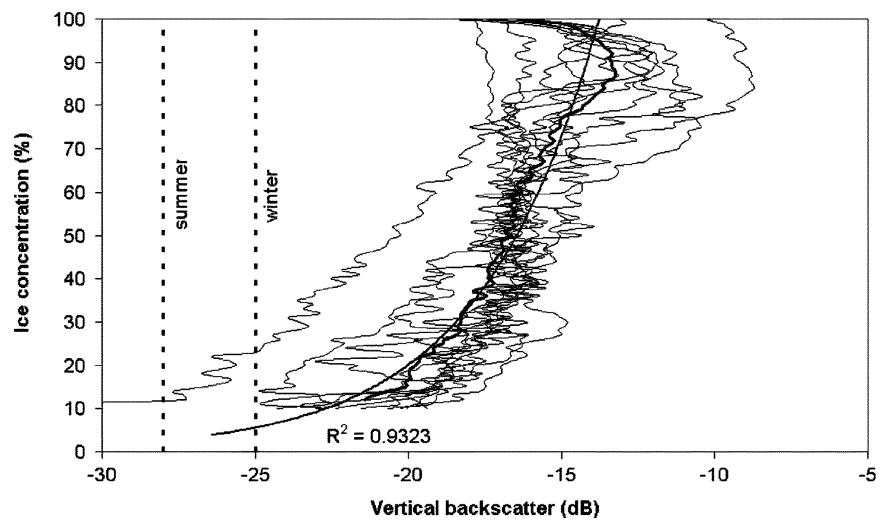

(b)

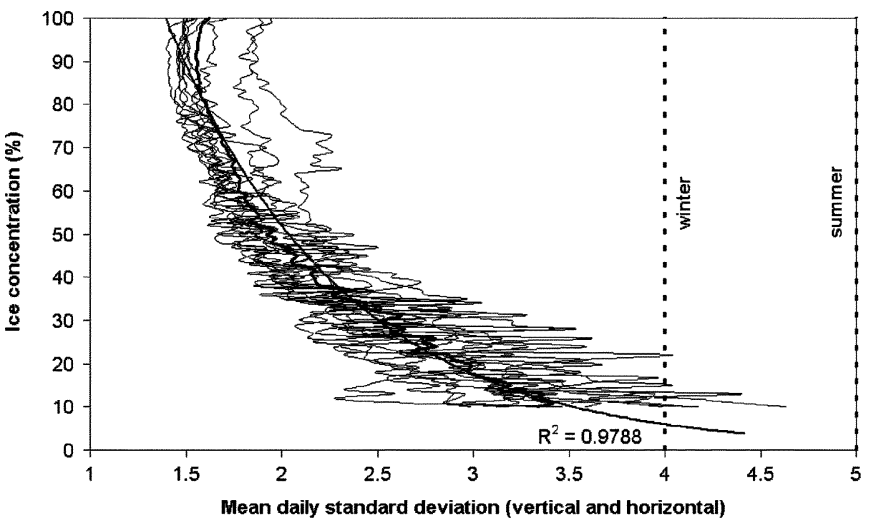

(c)

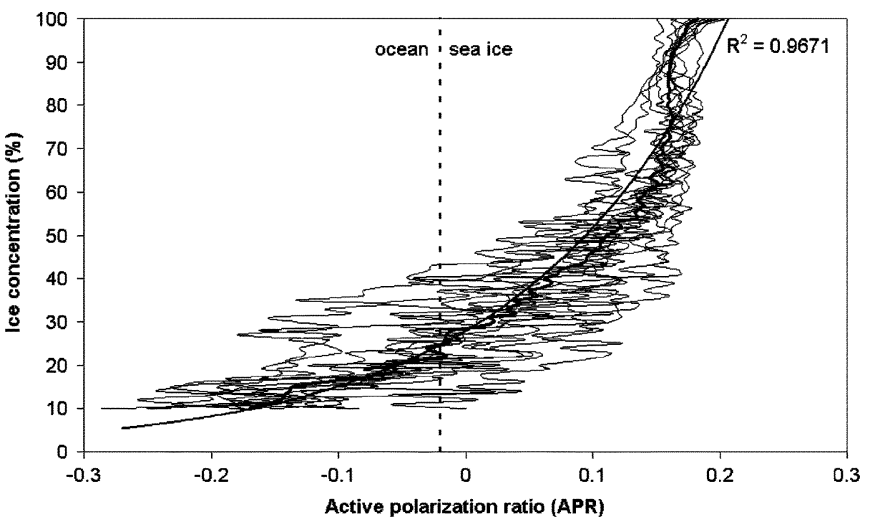

(d)

Fig. 3. Colocation of NT ice concentration and QS variables. (a) $\sigma_{0 \mathrm{H}}$. (b) $\sigma_{0 \mathrm{~V}}$. (c) STD. (d) APR. The thin lines are the daily mean values for each ice concentration for the first day of the month. The thick lines are the average of all the thin lines. Determined ice-ocean thresholds are indicated as dotted lines. 
higher APR than MYI at high ice concentrations, which is due to the higher incidence angle dependency for FYI because of stronger surface scattering. The high variability at lower ice concentrations has several causes. The two primary causes are that: 1) low ice concentrations are located mostly in the MIZ where melting and freezing events frequently occur, which influence the backscatter signature, and 2) that the lower the ice concentration, the more important the contribution from the wind signature over the ocean, which is more variable than ice signatures. Another reason for high variability is that low ice concentrations are spatially less abundant than high ice concentrations and their mean values are, therefore, statistically less significant. Variability also results from differences in resolution between the two datasets, SSM/I and QS. Having a resolution about four times smaller, QS pixels might detect both high and low ice concentrations in the same area where one SSM/I pixel detects medium ice concentration.

\section{New-ICe-Edge AlgORITHM}

As the statistical analysis has shown, a distinction between ice and ocean is possible with all variables $\sigma_{0 \mathrm{H}}, \sigma_{0 \mathrm{~V}}$, the $\mathrm{STD}_{\mathrm{V} / \mathrm{H}}$, and the APR. However, the first two variables do not have reliable thresholds at high wind speeds. In addition, MYI, and FYI have very distinct backscatter signatures, so the backscatter is not only dependent on the total ice concentration but also on the partial MYI and FYI concentration. The daily standard deviation is very sensitive to sudden melting events because these events cause a strong decrease in the backscatter, making it difficult to define a valid $\mathrm{STD}_{\mathrm{V} / \mathrm{H}}$ during the melting season. Also, pixels that are close to the coast are influenced by slopes where the backscatter varies strongly at different azimuth angles. Therefore, thresholding by using $\sigma_{0 \mathrm{H}}, \sigma_{0 \mathrm{~V}}$, or $\mathrm{STD}_{\mathrm{V} / \mathrm{H}}$ would probably underestimate the ice edge. Fig. 2(c) shows that only the APR has a clear threshold between open water and ice, with ice pixels having a mostly positive APR and ocean pixels a mostly negative APR. We, therefore, use the APR as the main variable to distinguish between ice and ocean. To also include the lowest distinguishable ice concentrations, an APR threshold of -0.02 is chosen. Since the effective QS resolution is $5-10 \mathrm{~km}$, but the pixel size is $2.225 \mathrm{~km}$, we increase the pixel size by averaging over a $3 \times 3$ pixel window to a pixel size of $6.675 \mathrm{~km}$. This gives us an additional advantage because we can extract the least ambiguous APR pixel value from each $3 \times 3$ pixel window by choosing the pixel with the highest absolute value. This parameter is called $\mathrm{APR}_{\mathrm{abs}}$.

In order to further eliminate possible ocean noise, we assigned the other variables, $\sigma_{0 \mathrm{H}}, \sigma_{0 \mathrm{~V}}$, and $\mathrm{STD}_{\mathrm{V} / \mathrm{H}}$ with very conservative threshold values, set by the maximum and minimum values for sea ice found by colocation with the NT ice concentration shown in Fig. 3. Because these three variables are very sensitive to temperature changes around the freezing/melting point, winter and summer thresholds differ. The algorithm can be summarized as follows:

$$
\begin{aligned}
& \operatorname{IF}\left(\left(\operatorname{APR}(i, j)>\operatorname{APR}_{0}\right) \operatorname{AND}\left(\operatorname{APR}_{\mathrm{abs}}(\mathrm{i}, \mathrm{j})>\operatorname{APR}_{0}\right)\right. \\
& \operatorname{AND}\left(\sigma_{0 \mathrm{~V}}(\mathrm{i}, \mathrm{j})>\sigma_{\mathrm{W} / \mathrm{S}}\right) \operatorname{AND}\left(\sigma_{0 \mathrm{H}}(\mathrm{i}, \mathrm{j})>\sigma_{\mathrm{W} / \mathrm{S}}\right) \\
& \left.\operatorname{AND}\left(\operatorname{STD}_{\mathrm{V} / \mathrm{H}}(\mathrm{i}, \mathrm{j})<\operatorname{STD}_{\mathrm{W} / \mathrm{S}}\right)\right) \\
& \operatorname{THEN}(\operatorname{pixel}(\mathrm{i}, \mathrm{j})=\text { "ice" }) \operatorname{ELSE}(\operatorname{pixel}(\mathrm{i}, \mathrm{j})=\text { "ocean" }),
\end{aligned}
$$

TABLE I

ICE-OCEAN THRESHOLDS FOR THE FOUR PARAMETERS

\begin{tabular}{ccc}
\hline \hline Parameter & Winter & Summer \\
\hline $\mathrm{APR}$ & $>-0.02$ & $>-0.02$ \\
$\mathrm{APR}_{\mathrm{abs}}$ & $>-0.02$ & $>-0.02$ \\
$\sigma_{0 \mathrm{H}}$ & $>-25 \mathrm{~dB}$ & $>-28 \mathrm{~dB}$ \\
$\sigma_{0 \mathrm{~V}}$ & $>-25 \mathrm{~dB}$ & $>-28 \mathrm{~dB}$ \\
$\mathrm{STD}_{\mathrm{V} / \mathrm{H}}$ & $<4$ & $<5$ \\
\hline \hline
\end{tabular}

All relations need to be fulfilled for pixels to be classified as ice.

where $(\mathrm{i}, \mathrm{j})$ is the pixel location, $\mathrm{APR}_{0}$ is the primary ice-ocean threshold of the main variables $\mathrm{APR}$ and $\mathrm{APR}_{\mathrm{abs}}$, while $\sigma_{\mathrm{W} / \mathrm{S}}$ and $\mathrm{STD}_{\mathrm{W} / \mathrm{S}}$ are the secondary season-dependent (winter/summer) thresholds used to eliminate ocean noise. All thresholds are extracted from Figs. 2 and 3 and are summarized in Table I. Because melting reduces the backscatter and increases the daily variation, the thresholds for $\sigma_{0 \mathrm{H}}$ and $\sigma_{0 \mathrm{~V}}$ are lowered from -25 to $-28 \mathrm{~dB}$, and the threshold for $\mathrm{STD}_{\mathrm{V} / \mathrm{H}}$ is raised from 4 to 5 during summer.

One of the main advantages of QS is its good temporal resolution and good coverage in the high Arctic. However, at lower latitudes, the daily standard deviation images have less significance since they are based on fewer measurements and from fewer satellite orbits. Ocean noise at lower latitudes that results from high wind speeds is, therefore, more difficult to eliminate by using $\mathrm{STD}_{\mathrm{V} / \mathrm{H}}$. A good first approach to eliminating ocean noise is to remove all ice pixels that are not attached to the land or to the main pack ice, considering that the ice cover mainly expands from the inner Arctic pack during the freezing season, a technique done in [18] using binary processing. Ice pixel removal can be accomplished by sequentially dilating a mask that includes land and a minimum Arctic pack ice by a $3 \times 3$ pixel window and applying an "AND" operator between the mask and the ice image resulting from the thresholding process until the number of ice pixels converges. This approach eliminates not only ocean noise but also ice pixels that are not attached to the main pack ice.

A daily composite sequence over the whole Arctic facilitates a different approach based on using the preceding day as a first approximation. Since ocean noise is spatially more variable than ice pixels from ice fields that are separated from the main pack, applying an "AND" operator between two days of thresholding eliminates some of the ocean noise but conserves ice fields that are spatially stable over these two days. Dilating the ice mask until convergence results in the daily extent. Longer periods of strong winds can still prevail as ocean noise, but during the melting season, when ice fields are separated from the main pack ice by melt and drift, the use of the previous day is especially effective in conserving single ice fields.

\section{RESULTS AND VALIDATION}

\section{A. Winter}

Fig. 4 shows all used variables as images and illustrates the resultant ice extent on March 11, 2003. At high latitudes, e.g., in the Barents Sea, the algorithm detects a clear ice edge. At lower latitudes, such as south Baffin Bay, the Labrador Sea, and the Atlantic Ocean, strong winds combined with relatively poor daily 

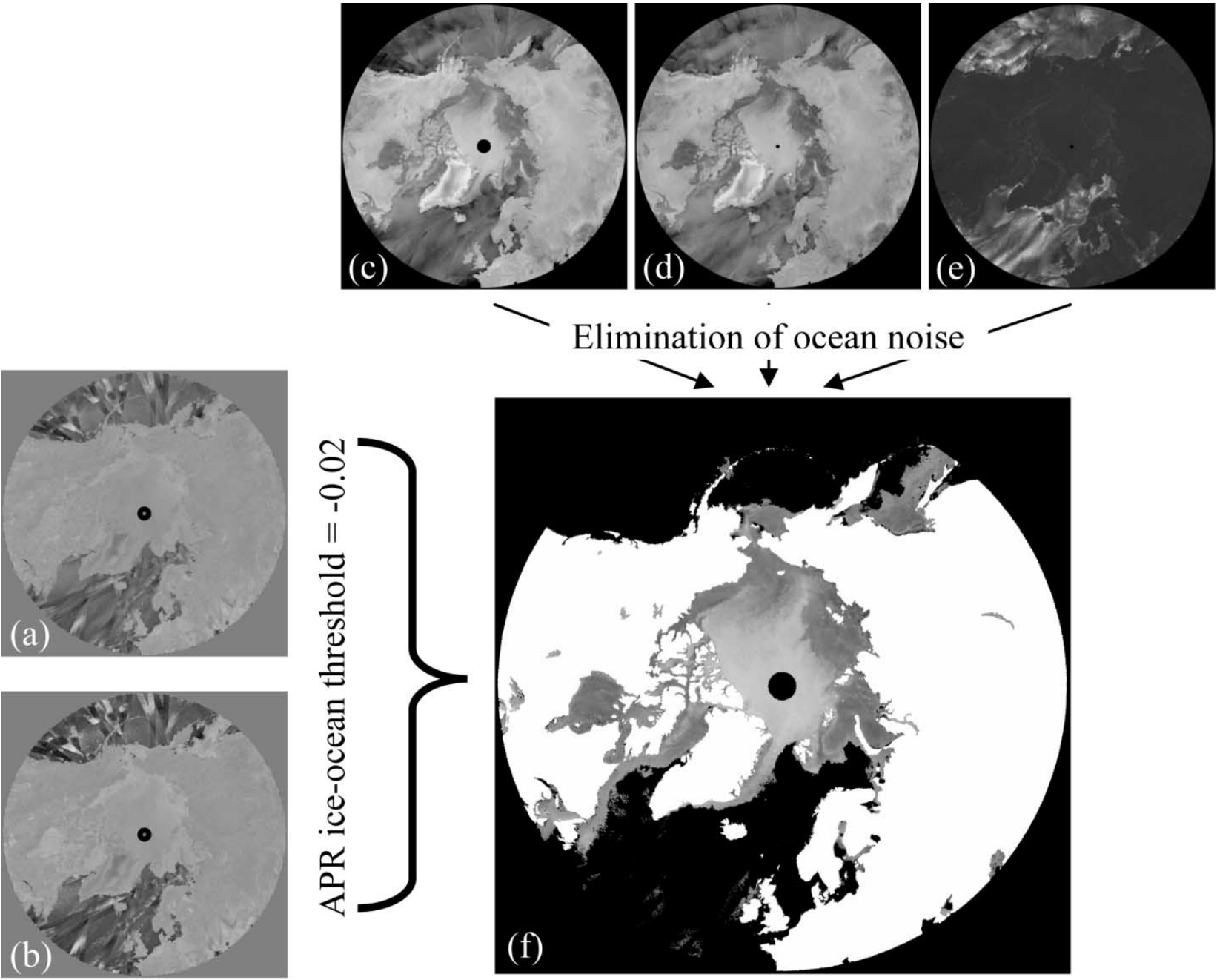

Fig. 4. Schematic presentation of the new algorithm using the (a) APR and (b) $\mathrm{APR}_{\mathrm{abs}}$ images as main variables and (c) $\sigma_{0 \mathrm{H}}$, (d) $\sigma_{0 \mathrm{~V}}$, and (e) $\mathrm{STD}_{\mathrm{V} / \mathrm{H}}$ as secondary variables to eliminate ocean noise to obtain (f) the total ice cover and ice edge. A land mask (in white) is applied on the result. The example is from March 11, 2003. Original data () NOAA/NESDIS/BYU

satellite coverage cause some ocean noise. Ocean noise that is not attached to the main pack ice is eliminated by the method explained in Section IV or by applying additional seasonal ice masks.

Statistical analysis of the new-ice edge and the BYU ice edge colocated with NT ice concentration show that the average ice edge is situated at about $14 \%$ lower ice concentration with the new algorithm than with the BYU algorithm, or 33\% and 47\%, respectively, between December 1, 2002, and May 1, 2003 (Fig. 5). The following detailed study shows, however, that the new-ice edge algorithm is able to detect even lower ice concentrations. The Barents Sea is a crucial area for fishing and submarine operations during winter so we concentrate our validation in this region.

On March 11 and 13, 2003, the Barents Sea is well covered by RS images, and we are able to validate the QS ice edge at very high resolution, shown in Fig. 6. The QS ice edge from March 11, 2003, calculated using the new algorithm, is superimposed as a black line. The BYU ice edge of the same day is superimposed in white. Over all, the new-ice edge is in average about $15-20 \mathrm{~km}$ further out at sea than the BYU ice mask, but the maximum distance between the two ice edges can extend as

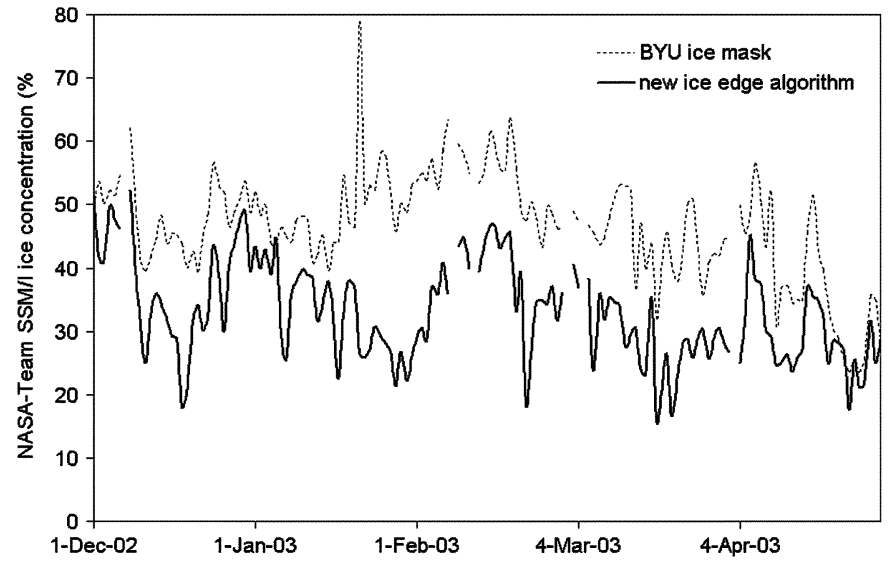

Fig. 5. Average NT ice concentration along the new-ice edge and the BYU ice edge over the whole Arctic region from December 1, 2002 to May 1, 2003.

much as $50 \mathrm{~km}$. In general this distance is the transition zone from heavy pack ice to open water and is of the order of the daily spatial variation of the ice edge. Due to the reduction in resolution in our algorithm, the BYU ice edge has a smoother appearance, but most of the time is well inside the pack ice and 


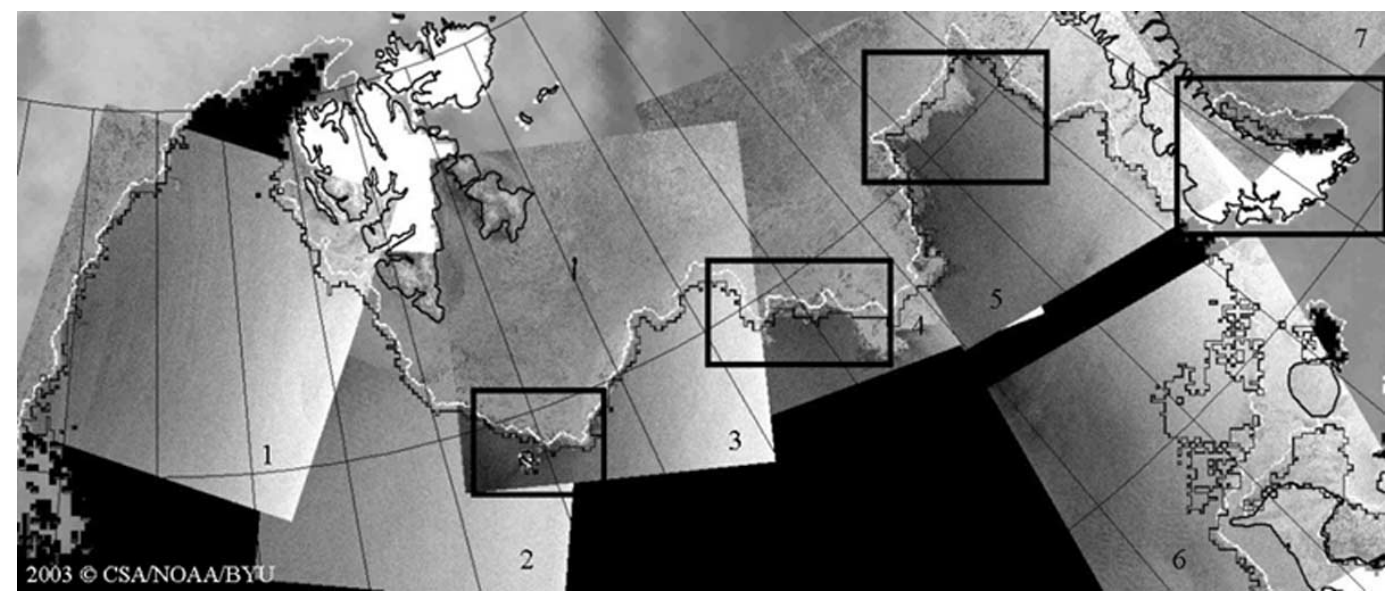

Fig. 6. RS SAR images in the Barents Sea colocated with the QS ice edge from March 11, 2003. Scenes 2 and 4 from the left and in the upper right corner (7) (east of Novaya Zemlya) are from March 13, 2003. The black line is the new-ice edge from March 11, 2003, and the white line is the BYU ice edge. The black rectangles indicate the location of the detailed analysis of Fig. 8-10.
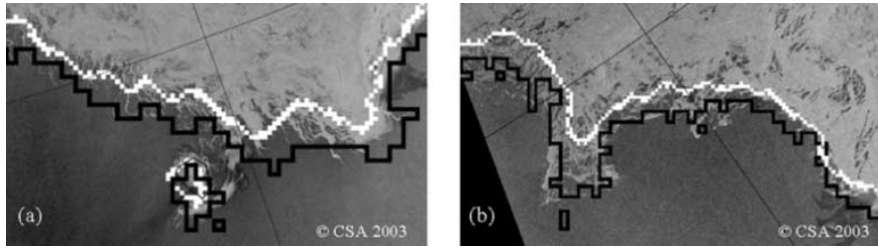

Fig. 7. Detection of low ice concentration and ice streaks by RS on (a) March 11, 2003, and (b) March 13, 2003, in the western and eastern Barents Sea, respectively. The black line is the new-ice edge. The white line is the BYU ice edge.

underestimates the real ice extent. Some high-resolution samples examined in the following illustrate several issues in detail.

1) Very Low Ice Concentration: On March 11, the MIZ around Bjørnøya shows several ice streaks extending about $10 \mathrm{~km}$ out to sea from denser ice fields [Fig. 7(a)]. The new algorithm captures such light ice conditions inside the ice edge, whereas the BYU ice mask excludes them. Also, on March 13 [Fig. 7(b)], such ice streaks and low ice concentration fields were present in the eastern Barents Sea and were detected by the new algorithm. Some of these low ice concentration can be estimated as low as $10 \%$.

2) Polynyas: Between March 11-13, a polynya formed southeast of Novaya Zemlya (Fig. 8). The new algorithm correctly detected the polynya edge, whereas the BYU ice edge overestimated the polynya width by about $50 \%$. SAR images can be very ambiguous in detecting open water [31], and in this case, it is not completely clear from the SAR if the polynya is completely ice free. Having shown that our algorithm detects very low ice concentration, QS confirms open water areas inside polynyas if the size and persistence of the open water area corresponds to the spatial $(\sim 7 \mathrm{~km})$ and temporal $(36-\mathrm{h})$ resolution of the composite image.

3) Strong Off-Ice Winds, New-Ice Formation, and Temporal Variability of the Ice Edge: The QS image is a 36-h composite, and therefore, the detected ice edge is subject to space/time aliasing. Thus, comparison of these composites with RS snap shots is not straight forward; however, it is possible to draw some conclusions on the temporal variability of the ice edge.

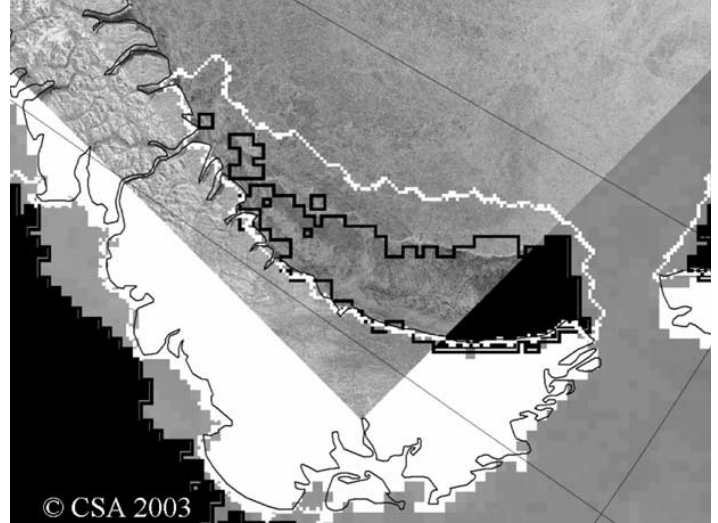

Fig. 8. Polynya observed by RS in the south east of Novaya Zemlya on March 13, 2003. The black line is the new-ice edge. The white line is the BYU ice edge.

As long as the ice conditions are spatially stable over the 36-h period, we expect the algorithm to have an accuracy commensurate with the image resolution of $7 \mathrm{~km}$. The accuracy decreases as soon as strong geophysical dynamics occur, such as significant ice drift, deformation, growth, and melt. Off-ice winds are often combined with new-ice formation. Fig. 9 shows that such an event occurred in the eastern Barents Sea about $200 \mathrm{~km}$ west of Novaya Zemlya on March 11, when ice was blown southward and/or new ice was formed by cold northerly winds over a large area. The QS composite includes all data taken between 10h44 on March 10 and 22h07 on March 11. The RS image was taken at $03 \mathrm{~h} 44$ on March 11, about in the middle of the composite period. The QS time series from March 9-11 shows a strong southward ice motion. The new QS ice edge underestimates the ice extent in this case by about $50 \mathrm{~km}$, which should correspond to the displacement of the ice edge in a time frame of $17 \mathrm{~h}$ from $10 \mathrm{~h} 44$ to $03 \mathrm{~h} 44$ the next day). Individual thresholding of each variable shows that only the APR fails to detect this new-ice area, confirming our choice of conservative thresholds for $\sigma_{0 \mathrm{H}}, \sigma_{0 \mathrm{~V}}$, and $\mathrm{STD}_{\mathrm{V} / \mathrm{H}}$. However, it is obvious from Fig. 8 that the new-ice edge (black line) delimits two different ice regions. The SAR signature is not completely clear: one might interpret the new-ice area as frazil ice streaks. Frazil, i.e., floating 


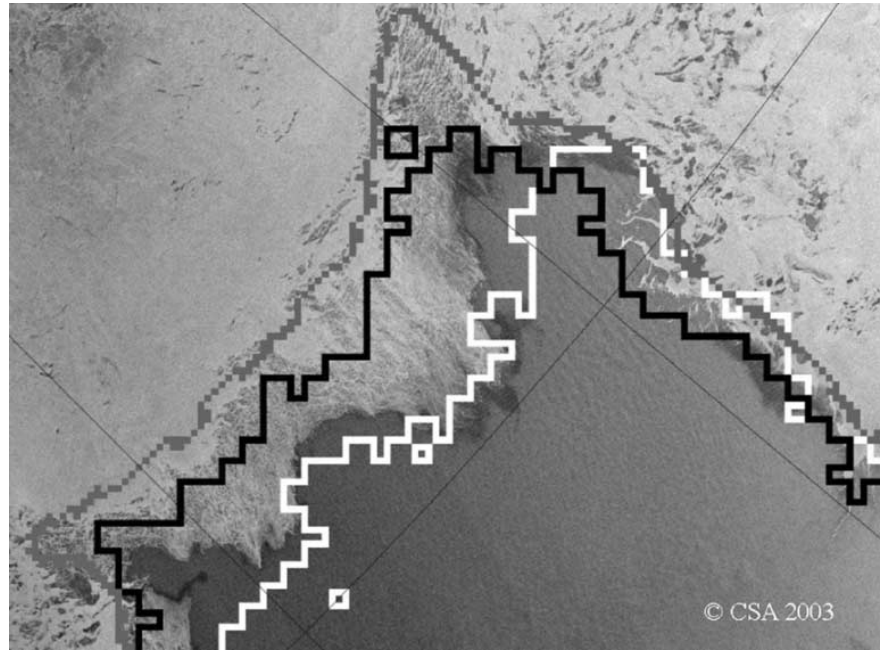

Fig. 9. RS image of new-ice formation over a vast region in the eastern Barents Sea. The black line is the new-ice edge from March 11, 2003. The gray line is the BYU ice edge from March 11, 2003, and the white line is the new-ice edge from March 13, 2003.

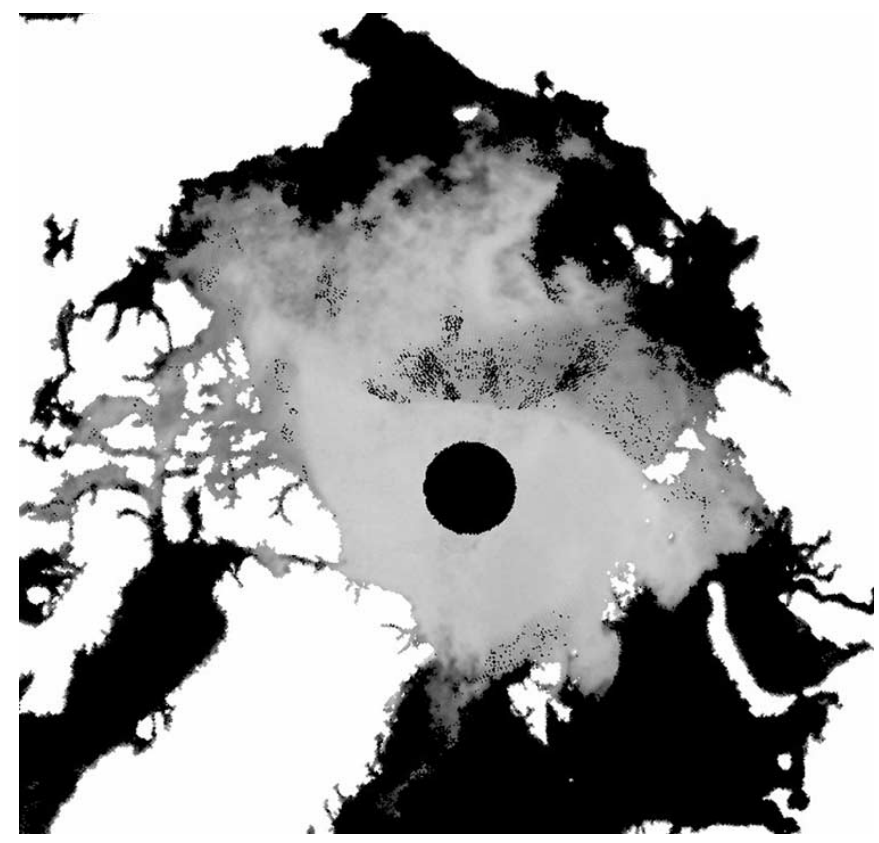

Fig. 10. QS ice extent on September 1, 2003.

ice crystals, are sensitive to wave action and could have a QS signature for the APR similar to open water. As the ice edge was relatively stable between March 11 and 13, the correct ice edge is detected on March 13, (white line in Fig. 9).

\section{B. Summer}

Fig. 10 shows a summer QS ice cover image from September 1, 2003, for the Arctic region. During summer, melting events are visible in the QS images as a strong drop in backscatter, i.e., a darker appearance, e.g., the area north of Siberia in Fig. 9. The drop in backscatter results from Ku-band's high sensitivity to increased liquid water at the snow/ice surface during melting that attenuates the backscatter. Sudden melting events during the 36-h integration period increase the daily standard deviation to such a level that these areas may be classified as open water. In
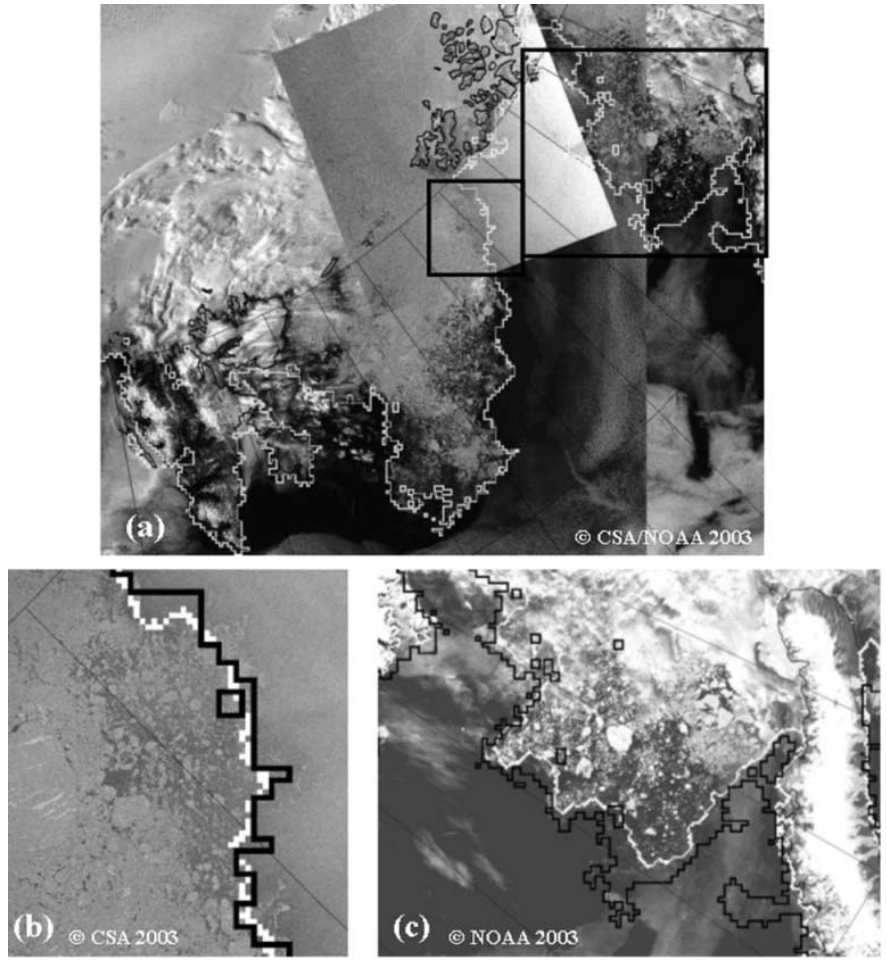

Fig. 11. (a) Ice edge in the Barents Sea on July 28, 2003, seen by AVHRR and RS. The white line is the detected new-ice edge from QS. Comparison between the new-ice edge (black line) and the BYU ice edge (white line) (b) south of Franz Josef Land and (c) west of Novaya Zemlya. The black rectangles show the position of (b) and (c). Original Images (C) CSA 2003 and NOAA/NESDIS.

the high Arctic, they are easily detectable by comparison with images from the previous day. Along the MIZ though, this effect can induce errors in the ice edge location that are difficult to detect. When the ice tongue and the long ice floes in the Greenland Sea have been observed over several days, we can use information from the previous day in the algorithm to successfully conserve such separated ice floes.

Fig. 11 shows the new and the BYU ice edge in the Barents Sea superimposed on AVHRR and RS images from July 28, 2003. In summer, the ice edge may also include very low ice concentrations of about $10 \%$. In some cases, the BYU ice mask also picked up such low ice concentrations and both ice edges correspond very well to each other. The good agreement in this case may be due to stable conditions of calm winds, and no new ice is formed.

\section{DISCUSSION}

The new-ice edge algorithm proved to be quite reliable year round. The aim of this algorithm was to improve ice edge detection in order to include the lowest ice concentration possible. Indeed, with an accuracy of about $10 \mathrm{~km}$, we were able to detect lower ice concentration than the previously provided BYU ice mask.

However, the ice edge has a different significance for different users and applications. Characteristics that play into the definition of the ice edge are ice type, ice concentration, resolution, and temporal validity. What kind of ice type, for example, is considered an important ice cover? Should floating ice crystals like frazil and slush be considered as an ice cover? If not, at which 
stage during their evolution into nilas and thin ice, i.e., at which ice thickness, do we set the limit? Many of these characteristics are still not reliably detected from space. Ice concentration also has a vague definition because it is dependent on the integrated area to be considered. Since the ice edge is a dynamic feature, its resolution and temporal variability are defined by the strength of the geophysical forcing, the thermodynamics, and the kinetics it undergoes.

The QS composite data integrated over a 36-h period seemed to correspond very well with RS snapshots from the middle of the integration period. The only ambiguities occurred with new-ice areas, frazil, or nilas, which even high-resolution SAR could not definitively distinguish. Estimating a high ice drift to be of the order of $1 \mathrm{~km} / \mathrm{h}$ and a minimum transition time of at least $3 \mathrm{~h}$ from the instant the data are taken until the moment the final user could receive the data, a resolution of $7 \mathrm{~km}$ is close to optimal accuracy for near-real-time operation based on satellite data alone. Modeling with the help of atmospheric data can, however, improve the accuracy, but this topic is outside the scope of this discussion.

A 36-h integration period could potentially mean an error of several tens of kilometers, considering an average ice edge position. With this in mind, it is not clear from our study if: 1) the new-ice edge algorithm detects an average position of the ice edge or 2) if sea ice that was present only for a short period has enough impact in the composite signature to be detected as ice. This is generally the case for all composite images and needs to be addressed in future studies. Unfortunately, high-resolution coverage of SAR is still too sparse to investigate this issue. Considering that our high-resolution study shows that the ice edge was mostly outside the ice cover observed by SAR and AVHRR even for very low ice concentration, we could assume the latter case. Hence, the vast new-ice area $200 \mathrm{~km}$ west of Novaya Zemlya on March 11, 2003, not detected by our algorithm may be frazil streaks and could be considered as open water. This makes sense in the way that floating ice crystals do not present a fatal hazard for shipping operations.

For climate, geophysical, and other modeling studies, the QS ice edge provides input data at a significantly (two to four times) better resolution than the commonly used SSM/I. Depending on the required temporal resolution, several days of QS data could be averaged to totally exclude ocean noise but would of course result in a loss of spatial resolution. For high-resolution studies and modeling, the ice edge alone might not be enough to describe the ice conditions because a good estimation of the ice concentration is necessary for the study of the MIZ and its importance to the climate, biology, etc. The statistical analysis from Section III shows that QS data also has the potential to provide information about the total and partial ice concentrations, which will be investigated in future studies.

The degree of resolution enhancement is dependent on the density and number of measurements and, therefore, on the length of the integration period. To cover the whole Arctic in one composite including the most southern sea-ice areas, i.e., the Sea of Okotsk, the Bering Sea, and the Labrador Sea, a 36-h integration period is necessary. Smaller regions, especially at higher latitudes, could be covered with a shorter integration time. However, there is a balance between the minimum integration time and the number of measurements to reach the optimal resolution enhancement. The Barents Sea, for example, could be covered with 3-6 satellite orbits meaning an integration period of $5-10 \mathrm{~h}$. This would mean that the final resolution of $7 \mathrm{~km}$ would already include most of the temporal geophysical variability due to ice drift. The December 2002 launch of a second SeaWinds scatterometer onboard ADEOS-2 with a 12-h phase difference to QuikScat temporarily doubled the number of measurements and reduced all necessary integration times by half. Such a reduction in integration time or increase in orbits would enhance the operational near-real-time use and enable more precise input data for modeling with a higher timely resolution. Unfortunately, ADEOS-2 failed in October 2003, and at this time no follow-up Ku-band scatterometer mission is planned. A possible combination and application of this algorithm with data from the future C-band fan-beam advanced scatterometer on the first Meteorological Operational Polar Satellites (METOP) of the European Organization for the Exploitation of Meteorological Satellites (EUMETSAT), to be launched in 2005, should be investigated in the future.

\section{CONCLUSION}

An ice edge algorithm was developed to extract the total ice cover, including very low ice concentration, from QuikScat/SeaWinds scatterometer enhanced-resolution data. The new algorithm is based on simple thresholding of the available variables, i.e., the backscatter in vertical and horizontal polarizations, the active polarization ratio, and the daily standard deviation. An APR value of -0.02 was used as the main threshold in the ice ocean discrimination. As the other variables are sensitive to surface changes due to melting, they were used with very conservative thresholds to further eliminate ocean noise. The thresholds were defined through statistical analysis by colocation of QS data with Greenland ice charts and with NT ice concentration data. In order to also detect single ice fields that occur especially in summer by separation of the Arctic pack through melting, the history of the ice cover, i.e., information from the preceding day, was taken into account. Validation with high-resolution RS images during winter and AVHRR images during summer showed that the algorithm successfully detected very low ice concentrations of about $10 \%$ over the whole year and correctly identified polynyas during winter. Falsely identified ice in the ocean (ocean noise) still occurred at lower latitudes where the multirepeat satellite coverage is sparse. Strong sudden surface melting events during summer caused important variations in backscatter ice signatures and increased the daily standard deviation enough to falsely identify ice as open water. Errors caused by ocean noise and surface melting events could be easily identified and manually corrected by comparing subsequent days.

In one case, the algorithm did not identify a new-ice region visible in SAR images. The SAR signatures, however, could be interpreted as streaks of frazil ice and wave action inside frazil ice, which could have a similar QS signature to open water. Since frazil ice is not a solid ice cover, it may still be reasonable to classify such an area as open water. Depending on the definition of the MIZ and the transition from the Arctic pack 
to open water, the new algorithm defines the ice edge about $10-20 \mathrm{~km}$ farther seaward than the BYU ice mask. In cases like off-ice winds and ice tongues, the difference can be of the order of $50 \mathrm{~km}$. Although the enhanced-resolution data are gridded in a $2.225-\mathrm{km}$ grid, the data were reduced by averaging $3 \times 3$ pixel windows to its effective resolution of $\sim 7 \mathrm{~km}$. Considering the spatial variation due to the dynamic nature of the ice cover during the integration period for the composite and the necessary time to transfer the data to its end users for near real-time operation, the maximum resolution of a reliable ice edge definition seems to have been reached.

\section{ACKNOWLEDGMENT}

Travel support was given by the EUMETSAT Satellite Application Facilities program. The original images of QS, AVHRR, and RS are under copyright of Brigham Young University, NOAA/NESDIS, and CSA 2003, respectively. Thanks to K. Dedrick (NIC).

\section{REFERENCES}

[1] Q. P. Remund and D. G. Long, "Sea ice mapping algorithm for QuikScat and SeaWinds," in Proc. IGARSS, Seattle, WA, July 1998, pp. 1686-1688.

[2] B. Rudels, "The thermohaline circulation of the Arctic ocean and the Greenland sea," Philos. Trans. R. Soc. London, Ser. A-Math., vol. 352, no. 1699 , pp. 287-299, 1995.

[3] D. C. Chapman, "Dense water formation beneath a time-dependent coastal polynya," J. Phys. Oceanogr., vol. 29, no. 4, pp. 807-820, 1999.

[4] J. Haarpaintner, P. M. Haugan, and J.-C. Gascard, "Interannual variability of the Storfjorden ice cover and ice production observed by ERS-2 SAR," Ann. Glaciol., vol. 33, pp. 430-436, 2001.

[5] O. M. Johannessen, E. V. Shalina, and M. W. Miles, "Satellite evidence for an Arctic sea ice cover in transformation," Science, vol. 286, no. 5446, pp. 1937-1939, 1999.

[6] S. Andersen, "Evaluation of SSM/I sea ice algorithms for use in the SAF on ocean and sea ice," Danish Meteorol. Inst., Copenhagen, Denmark, Tech. Rep. 00-10, 2000.

[7] C. L. Parkinson, J. C. Comiso, H. J. Zwally, D. J. Cavalieri, P. Gloersen, and W. J. Campbell, "Antarctic sea ice, 1973-1976: Satellite Passive Microwave observations," National Aeronautics and Space Administration, Washington, DC, Special Rep. NASA SP-489, 1987.

[8] W. N. Meier, M. L. Van Woert, and C. Bertoia, "Evaluation of operational SSM/I ice-concentration algorithms," Ann. Glaciol., vol. 33, pp. 102-108, 2001

[9] K. C. Partington, "A data fusion algorithm for mapping sea-ice concentrations from Special Sensor Microwave/Imager data," IEEE Trans. Geosci. Remote Sensing, vol. 38, pp. 1947-1958, May 2000.

[10] D. Cavalieri, P. Gloersen, and W. J. Campbell, "Determination of sea-ice parameters with the NIMBUS 7 SMMR," J. Geophys. Res., vol. 89, no. D4, pp. 5355-5369, 1984.

[11] J. R. Hollinger, R. Lo, G. Poe, R. Savage, and J. Pierce, "Special Sensor Microwave/Imager calibration/validation," Naval Res. Lab., Washington, DC, Final Report, 1991.

[12] M. L. Van Woert, W. N. Meier, C. Z. Zou, J. A. Beesley, and P. D. Hovey, "Satellite validation of the May 2000 sea ice concentration fields from the polar ice prediction system," Can. J. Remote Sens., vol. 27, no. 5, pp. 443-456, 2001

[13] S. Andersen, S. Kern, and H. Schyberg, "Improved retrieval of sea ice total concentration from spaceborne passive microwave observations using numerical weather prediction model fields: An intercomparison of eight algorithms," Remote Sens. Environ., submitted for publication.

[14] T. Lungu, "NASA Quick Scatterometer-QuikSCAT science data product user's manual: Overview and geophysical data products. Version 2.2," Jet Propulsion Lab., Calif. Inst. Technol., Pasadena, CA, JPL Rep. D-18053, 2001
[15] D. G. Long and M. R. Drinkwater, "Cryosphere application of NSCAT data," IEEE Trans. Geosci. Remote Sensing, vol. 37, pp. 1671-1684, May 1999.

[16] D. G. Long, P. J. Hardin, and P. T. Whiting, "Resolution enhancement of spaceborne scatterometer data," IEEE Trans. Geosci. Remote Sensing, vol. 31, pp. 700-715, May 1993.

[17] D. S. Early and D. G. Long, "Image reconstruction and enhanced resolution imaging from irregular samples," IEEE Trans. Geosci. Remote Sensing, vol. 39, pp. 291-302, Feb. 2001.

[18] Q. P. Remund and D. G. Long, "Sea ice extent mapping using Ku-band scatterometer data," J. Geophys. Res., vol. 104, no. C5, pp. 11 515-11 527, 1999.

[19] R. De Abreu, K. Wilson, M. Arkett, and D. Langlois, "Evaluating the use of QuikSCAT data for operational sea ice monitoring," in Proc. IGARSS, ON, Canada, June 2002.

[20] R. Tonboe and R. Ezraty, "Monitoring of new-ice in Greenland waters," in Proc. IGARSS, Toronto, ON, Canada, June 2002, pp. 1932-1934.

[21] S. V. Nghiem, R. Kwok, S. H. Yueh, and M. R. Drinkwater, "Polarimetric signatures of sea ice-1. Theoretical models," J. Geophys. Res., vol. 100, no. C7, pp. 13 665-13 679, 1995.

[22] R. Ezraty and A. Cavanié, "Intercomparison of backscatter maps over arctic sea ice from NSCAT and the ERS scatterometer," J. Geophys. Res., vol. 104, no. C5, pp. 11471-11483, 1999.

[23] R. Tonboe and J. Haarpaintner, "Implementation of QuikScat/SeaWinds data in the EUMETSAT ocean \& sea ice ice product," Danish Meteorol. Inst., Copenhagen, Denmark, Tech. Rep. 03-13, 2003.

[24] S. H. Yueh, R. Kwok, S.-H. Lou, and W.-Y. Tsai, "Sea ice identification using dual-polarized Ku-band scatterometer data," IEEE Trans. Geosci. Remote Sensing, vol. 35, pp. 560-569, May 1997.

[25] R. Tonboe, S. Andersen, and L. Toudal, "Anomalous winter sea ice backscatter and brightness temperatures," Danish Meteorol. Inst., Copenhagen, Denmark, Sci. Rep. 03-13, 2003.

[26] D. G. Long and D. Daum, "Spatial resolution enhancement of SSM/I data," IEEE Trans. Geosci. Remote Sensing, vol. 36, pp. 407-417, Mar. 1997.

[27] D. G. Long, M. R. Drinkwater, B. Holt, S. Saatchi, and C. Bertoia, "Global ice and land climate studies using scatterometer image data," Trans. Amer. Geophys. Union, vol. 82, no. 43, p. 503, 2001.

[28] D. G. Long, "Standard BYU QuikScat/SeaWinds land/ice image products," Brigham Young Univ., Provo, UT, QuikScat Image Product documentation, 2000.

[29] D. S. Early and D. G. Long, "Azimuthal modulation of C-band scatterometer $\sigma^{0}$ over southern ocean sea ice," IEEE Trans. Geosci. Remote Sensing, vol. 35, pp. 1201-1209, Sept. 1997.

[30] R. Ezraty and A. Cavanié, "Construction and evaluation of $12.5 \mathrm{~km}$ grid NSCAT backscatter maps over the Arctic sea ice," IEEE Trans. Geosci. Remote Sensing, vol. 37, pp. 1685-1697, May 1999.

[31] J. Haarpaintner, J.-C. Gascard, and P. M. Haugan, "Ice production and brine formation in Storfjorden, Svalbard," J. Geophys. Res., vol. 106, no. C7, pp. 14 001-14 013, 2001.

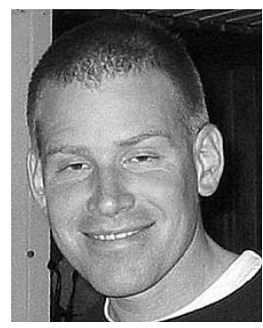

Jörg Haarpaintner received the maitrise (M.Sc.) degree in applied physics and the Ph.D. degree in physical methods for remote sensing, in 1995 and 2001, respectively, both from the University of Versailles-St.Quentin, Versailles, France. He conducted his Ph.D. research as an EU Fellow at the Norwegian Polar Institute in Troms $\varnothing$, Norway, and spent one year at the University Courses on Svalbard.

Thereafter he worked at the Cooperative Research Centre for Greenhouse Accounting, Canberra, Australia, before receiving a NASA Post-Doc grant to join the National Ice Center, Washington, DC, as a UCAR Visiting Scientist. He is currently continuing his research at the Ice Service of the Norwegian Meteorological Institute, Troms $\emptyset$. His professional interests include sea ice physics, remote sensing, climate change, and sustainable international development.

Dr. Haarpaintner is a member of the American Geophysical Union. 


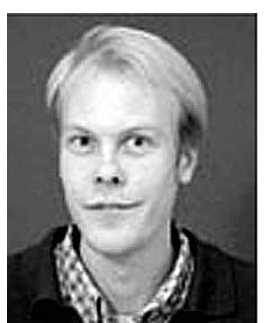

Rasmus T. Tonboe received the M.Sc. degree in geology from University of Aarhus, Aarhus, Denmark, in 1997, and the Ph.D. degree in geophysics from University of Copenhagen, Copenhagen, Denmark, in 2004.

$\mathrm{He}$ has been with the Greenland Ice Service, Danish Meteorological Institute, Copenhagen, since 1997. His research interests include both active and passive microwave remote sensing of sea ice conditions and properties.

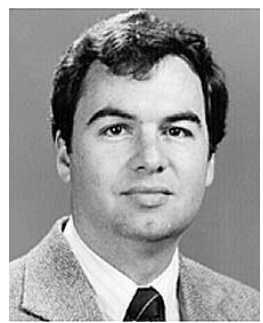

David G. Long (S'80-SM'98) received the Ph.D. degree in electrical engineering from the University of Southern California, Los Angeles, in 1989.

From 1983 to 1990 , he was with the National Aeronautics and Space Administration (NASA) Jet Propulsion Laboratory (JPL), Pasadena, CA, where he developed advanced radar remote sensing systems. While at JPL, he was the Senior Project Engineer on the NASA Scatterometer (NSCAT) project, which was flown aboard the Japanese Advanced Earth Observing System (ADEOS) from 1996 to 1997. He was also the Experiment Manager and Project Engineer for the SCANSCAT scatterometer (now known as SeaWinds). In 1990, he joined the Department of Electrical and Computer Engineering, Brigham Young University (BYU), Provo, UT, where he currently teaches upper division and graduate courses in communications, microwave remote sensing, radar, and signal processing, is the Director of BYU's Center for Remote Sensing, and is the Head of the Microwave Earth Remote Sensing Laboratory. He is the Principal Investigator on several NASA-sponsored interdisciplinary research projects in microwave remote sensing and innovative radar systems. He has numerous publications in signal processing and radar scatterometry. His research interests include microwave remote sensing, radar, polar ice, signal processing, estimation theory, and mesoscale atmospheric dynamics. He has over 250 publications in the open literature.

Dr. Long has received the NASA Certificate of Recognition several times.

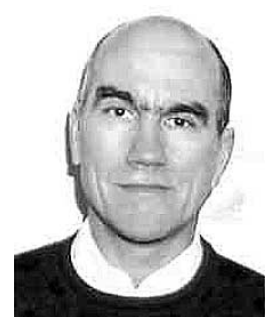

Michael L. Van Woert received the B.S. degree in physics from the University of California, Davis, in 1976, and the Ph.D. degree in oceanography from the University of California, San Diego, Scripps Institution of Oceanography, La Jolla, in 1983.

$\mathrm{He}$ has been with SeaSpace, Inc. for nine years and then moved to Washington, DC, where he managed NASA's Office of Physical Oceanography and the Office of Naval Research's High Latitude Programs. He is currently the Chief Scientist for the National Ice Center, Washington, DC. 